\title{
Tumor volume is an independent predictor of survival in patients with malignant pleural mesothelioma
}

\author{
Diana Y Kircheva ${ }^{1}$, Aliya Husain²${ }^{2}$ Sydeaka Watso ${ }^{3}$, Samuel Armato ${ }^{4}$, Hedy Kindler ${ }^{5}$, Wickii T Vigneswaran ${ }^{\text {* }}$ \\ From World Society of Cardiothoracic Surgeons 25th Anniversary Congress, Edinburgh \\ Edinburgh, UK. 19-22 September 2015
}

\section{Background/Introduction}

Tumor histology and stage are predictors of survival in patients with malignant pleural mesothelioma (MPM). The TNM classification that is widely accepted for MPM has its limitations. Significance of tumor volume, a better representation of tumor burden is not routinely determined. We hypothesized tumor volume is a better predictor of survival and complimentary to $\mathrm{T}$ and $\mathrm{N}$ stage. Extended pleurectomy and decortication (EPD), a lung sparing procedure, provides an opportunity to measure the tumor volume and pathological stage.

\section{Aims/Objectives}

Evaluate the significance of tumor volume on overall survival in patients undergoing EPD for MPM.

\section{Method}

111 patients who underwent EPD for MPM formed the basis of this report. The following variables were assessed: age, gender, histology including percent epithelioid histology and pathological $\mathrm{T}$ and $\mathrm{N}$ stage. Tumor volume of resected specimens was measured using a water displacement method. A Cox regression model was used to identify significant predictors of survival. Kaplan-Meier was used to summarize overall and subgroup survival.

\section{Results}

There were 91 males and 20 females with a median age of 68 years (range 43-88 years). Median tumor volume was $560 \mathrm{ml}$ (range 100-2200 ml). Tumor volume was less than $300 \mathrm{ml}$ in 18 patients, between $301-600 \mathrm{cc}$ in

${ }^{1}$ Department of Surgery, University of Chicago Medicine, Chicago, IL 60637, USA

Full list of author information is available at the end of the article
Table 1

\begin{tabular}{lc}
\hline Volume & Median survival \\
\hline$<300 \mathrm{ml}$ & 2.25 years \\
$301-600 \mathrm{ml}$ & 1.62 years \\
$601-900 \mathrm{ml}$ & 1.06 years \\
$>900 \mathrm{ml}$ & 0.9 years \\
\hline
\end{tabular}

37 patients, 601-900 in 29 patients and >900cc in 25 patients. Five patients (4.5\%) died within 30 days of surgery. Overall two year survival from diagnosis was $48.3 \%$ and from EPD was $31.5 \%$. Tumor volume was a significant predictors of survival $(\mathrm{p}=0.001$, Table 1$)$ and $\mathrm{T}$ stage $(\mathrm{p}=0.05)$. No relationship between $\mathrm{N}$ stage and either tumor volume or histology was observed.

\section{Discussion/Conclusion}

Tumor volume is an independent predictor of survival in patients with MPM undergoing EPD.

Tumor volume is an important measure and is complimentary to TNM staging.

\section{Authors' details}

'Department of Surgery, University of Chicago Medicine, Chicago, IL 60637, USA. ${ }^{2}$ Department of Pathology, University of Chicago Medicine, Chicago, IL 60637, USA. ${ }^{3}$ Department of Biostatistics, University of Chicago Medicine, Chicago, IL 60637, USA. ${ }^{4}$ Department of Radiology, University of Chicago Medicine, Chicago, IL 60637, USA. ${ }^{5}$ Department of Medicine, University of Chicago Medicine, Chicago, IL 60637, USA.

Published: 16 December 2015

doi:10.1186/1749-8090-10-S1-A48

Cite this article as: Kircheva et al:: Tumor volume is an independent predictor of survival in patients with malignant pleural mesothelioma. Journal of Cardiothoracic Surgery 2015 10(Suppl 1):A48. 